\title{
5-Bromo-2-deoxyuridine activates DNA damage signalling responses and induces a senescence-like phenotype in p16-null lung cancer cells Joanne C. Masterson and Shirley O'Dea
}

\begin{abstract}
5-Bromo-2-deoxyuridine (BrdU) is a thymidine analogue that is incorporated into replicating DNA. Although originally designed as a chemotherapeutic agent, sublethal concentrations of BrdU have long been known to alter the growth and phenotype of a wide range of cell types. Mechanisms underlying these BrdU-mediated effects remain unknown, however. We have characterized the effects of BrdU on A549 lung cancer cells by examining DNA damage responses, cell cycle effects and phenotypic changes. A549 cells express wild-type p53, but are p16null. Sublethal concentrations of BrdU evoke a DNA damage response in these cells that involves the activation of Chk1, Chk2 and p53. Increased numbers of enlarged nuclei and multinucleated cells are evident in the treated populations. Cell cycle inhibition occurs, resulting in reduced proliferation and accumulation of cells in the $S$, $G_{2} / M$ and $G_{0}$ phases. BrdU induces an early inhibition of p21 expression that coincides with nuclear localization of proliferating cell nuclear antigen. Subsequently, p21 levels increase, whereas proliferating cell nuclear antigen levels decrease compared with control cells. Upregulation of p27
\end{abstract}

and p57 expression also occurs. By day 7 of exposure to BrdU, treated cells acquire a senescent-like phenotype with an increase in cell size, granularity and $\beta$ galactosidase activity. We conclude that BrdU induces a DNA damage response in A549 cells, which results in reduced proliferation mitotic exit and phenotypic changes that resemble senescence. Anti-Cancer Drugs 18:1053-1068 @ 2007 Lippincott Williams \& Wilkins.

Anti-Cancer Drugs 2007, 18:1053-1068

Keywords: 5-bromo-2-deoxyuridine, DNA damage, lung, mitotic exit, senescence

Institute of Immunology, Biology Department, National University of Ireland Maynooth, Ireland

Correspondence to Dr Shirley O'Dea, PhD, Biology Department, Institute of Immunology, NUI Maynooth, Maynooth, Co. Kildare, Ireland Tel: +3531708 6117; fax: +35317086337; e-mail: shirley.odea@nuim.ie

Received 12 March 2007 Accepted 6 May 2007

and phenotype in various cell types [14]. Subsequently, BrdU became known as a differentiating agent owing to its effects on the morphology and phenotype of a wide range of cell types in vitro and in vivo, including normal chondrocytes, muscle, molar, brain, pancreatic and blood cells [15-20], and leukaemic and lung cancer cells [21-24]. More recently, the Ayusawa group [25,26] has reported that $\mathrm{BrdU}$ induces a senescent-like phenotype in both normal and transformed cells. Senescence, particularly in transformed cells, remains relatively poorly defined; it is now unclear whether the phenotypic changes observed in BrdU-treated cells in earlier studies were, in fact, senescence-related events rather than true differentiation effects. The Ayusawa group in their reports did not address this question. The ability of a chemotherapeutic agent, such as BrdU, to induce differentiation or senescence is potentially a desirable side effect that can enhance its antitumour activity. Moreover, BrdU might have clinical potential as a differentiation therapeutic, distinct from its chemotherapeutic role. Conversely, it remains to be proved whether the induction of senescence in tumours is, in fact, advantageous. Evidence exists that senescent cells can alter the microenvironment surrounding preneoplastic
In addition to its DNA-damaging effects, early studies with BrdU revealed significant effects on cell morphology 
cells and may encourage tumour growth [27]. The cellular effects and the mechanisms of action of BrdU, therefore, require clarification in this context.

Suggested mechanisms underlying the effects of BrdU on gene expression and cell phenotype include DNA mutations, alterations in DNA methylation, altered interactions with DNA-binding proteins and reversal of the remodelling of regulatory DNA into specific chromatin architecture that occurs during cancer. BrdU-substituted DNA has an increased capacity to bind histones [28], nonhistone proteins [29] and chromosomal proteins [30], and might become concentrated in repetitive DNA nucleotide sequences [31]; such observations have, however, not yet been linked to downstream effects. The Ayusawa group speculates that BrdU incorporation into AT-rich inactive chromatins, such as in scaffold/ nuclear matrix attachment region (S/MAR) sequences, results in altered interactions with AT-binding ligands and leads to changes in gene expression consistent with senescence [32,33]. The mechanisms underlying the subsequent halting of the cell cycle and the induction of a senescence-like phenotype, however, remain unexamined and unexplained.

In this study, we have characterized the DNA damage response and cell cycle effects of BrdU in A549 lung cancer cells. The A549 cell line is widely used for lung studies. These adenocarcinoma-derived cells contain wild-type p53 and pRb but do not express p16, a protein usually required for senescence [34]. The cell line is also aneuploid and contains chromosomal abnormalities [35], and heterogenous subpopulations [36]. We report that the DNA damage response to BrdU in these cells involves the activation of Chk1, Chk2 and p53. Subsequent cell cycle effects include halts at $G_{0}, S$ and $G_{2} / M$ phases, and morphological changes consistent with the induction of a senescent-like phenotype. It has recently been proposed that the induction and maintenance of senescence requires the efficient activation of the DNA damage response pathways [37,38]. Our data are consistent with this and indicate that DNA damage responses in BrdUtreated cancer cells lead to the inhibition of cell cycles and to the establishment of a senescence-like phenotype.

\section{Materials and methods}

\section{Cell culture and 5-bromo-2-deoxyuridine treatment}

The A549 lung adenocarcinoma cell line was obtained from the European Collection of Cell Cultures (Salisbury, UK). Cells were routinely cultured in a $1: 1$ mixture of Dulbecco's modified Eagle's medium and Hams F12 (Gibco, Paisley, UK), supplemented with 5\% fetal bovine serum (Gibco) and $2 \mathrm{mmol} / \mathrm{l}$ of L-glutamine (Gibco). Cells were maintained in a humidified atmosphere containing $5 \% \mathrm{CO}_{2}$ and $95 \%$ air at $37^{\circ} \mathrm{C}$. Stock solutions of $10 \mathrm{mmol} / \mathrm{l}$ of BrdU (Sigma, Poole, UK) were prepared in sterile water and stored at $-20^{\circ} \mathrm{C}$. Cells were seeded at $0.3 \times 10^{3} / \mathrm{cm}^{2}$ in tissue-culture vessels, appropriate to each assay. After $24 \mathrm{~h} \mathrm{BrdU}$ was added at a final concentration of $10 \mu \mathrm{mol} / \mathrm{l}$ in a volume of $200 \mu \mathrm{l} / \mathrm{cm}^{2}$ (day 0). The medium was replaced with fresh BrdUcontaining medium on day 3 and cells were harvested for assays as appropriate.

\section{Cell proliferation}

Cells were seeded into 24-well plates and BrdU was added after $24 \mathrm{~h}$. At each time point, both suspension cells and adherent cells were harvested. Adherent cells were harvested by trypsinization. Viability counts were carried out using ethidium bromide/acridine orange staining and an ultraviolet microscope. Total cell counts were obtained by combining the suspension and adherent cell counts.

\section{Immunofluorescence}

Cells were seeded into eight-well chamber slides (Nalge Nunc, Naperville, Illinois, USA) and BrdU was added after $24 \mathrm{~h}$. At appropriate time points, cells were fixed in ice-cold methanol for $5 \mathrm{~min}$ and blocked in $20 \%$ serum. Cells were then incubated with antiphosphorylated Chk1 (Ser 345), antiphosphorylated Chk2 (Thr68), anti-p53, antiphosphorylated-p53 (Ser 15, 37 or 46), antiphosphorylated $\mathrm{Rb}$ (Ser 807/811) (Cell Signaling, New England Biolabs, Hitchin, UK), antiproliferating cell nuclear antigen (PCNA), anti-p27 (Sigma), anticyclin D1, anti-p57, anti-p21 (Santa Cruz Biotechnology, Heidelberg, Germany) or anti-actin (Sigma). Alexa 488 secondary antibodies (Molecular Probes, Invitrogen, Paisley, UK) were used for visualization. Nuclei were counterstained with DAPi (Sigma). Slides were mounted in fluorescent aqueous mounting media (Dako Cytomation, Galway, Ireland) and photomicrographs were acquired using a fluorescent microscope or confocal microscope, as indicated.

\section{Fluorescence flow cytometry}

Cells were seeded into $75-\mathrm{cm}^{2}$ tissue-culture flasks and BrdU was added after $24 \mathrm{~h}$. On day 7 of treatment, cells were harvested by trypsinization and washed twice in phosphate-buffered saline (PBS) before being fixed in $70 \%$ ice-cold ethanol. Cells were washed twice in PBS/1\% fetal bovine serum to remove ethanol and blocked with neat rabbit serum. For detection of p21, cells were incubated with anti-p21 antibody (Santa Cruz Biotechnology) followed by a secondary rabbit antimouse antibody conjugated to Alexa 488 fluorescent dye (Molecular Probes). For detection of cyclin B1, Ki-67 (BD Biosciences, Oxford, UK) and pan-keratin (Sigma), cells were incubated with primary antibodies conjugated to fluorescein isothiocyanate fluorescent dye. Fluorescence was detected using a FACScan flow cytometer (Becton Dickenson, BD Biosciences) and analysed using CellQuest software (Becton Dickenson, BD Biosciences). 


\section{Western blot analysis}

Cells were lysed in radioimmunoprecipitation (RIPA) buffer for total protein extracts. Ten micrograms of protein was separated by sodium dodecyl sulphatepolyacrylamide gel electrophoresis and transferred onto a nitrocellulose membrane. Blots were incubated with primary antibodies directed against either p53 (Cell Signaling), PCNA (Sigma), antiphosphorylated cdc-2 (Tyr15) (Cell Signaling) or anti-actin (Sigma), followed by incubation with horseradish peroxidase-labelled secondary antibody. Chemiluminescence detection was then carried out. Equal loading was confirmed by immunostaining for actin (Sigma).

\section{Cell cycle analysis}

Subsequent cell cycle analysis was determined using propidium iodide DNA stain. After incubation with fluorescein isothiocyanate-labelled cyclin B1, Ki-67 and pan-keratin antibodies, cell cycle analysis was carried out using propidium iodide (Sigma) and $100 \mu \mathrm{g} / \mathrm{ml}$ RNase (Sigma) solution diluted in PBS. Fluorescence was detected using a FACScan flow cytometer and analysed using CellQuest software.

\section{Assay for metabolic activity}

Cell metabolic activity was measured using CellTitre 96 Aqueous One Solution Cell Proliferation Assay (Promega, Southampton, UK). The kit was used according to the manufacturer's instructions and adapted for use in a 24well tissue-culture plate. Briefly, cells were seeded into 24-well plates and BrdU was added after $24 \mathrm{~h}$. On day 7 of treatment, the supernatant was removed and the 3-(4,5dimethylthiazol-2-yl)-5-(3-carboxymethoxyphenyl)-2-(4sulphophenyl)-2H-tetrazolium (MTS) salt reagent was added to the cells in fresh culture media and incubated for $1 \mathrm{~h}$ at $37^{\circ} \mathrm{C}$, in $5 \% \mathrm{CO}_{2}$. Absorbance was measured at $450 \mathrm{~nm}$ using a Labsystems Multiscan microplate reader (Labsystems, Helsinki, Finland).

\section{Senescence assays}

For lysosomal content and senescence-associated $\beta$ galactosidase (SA- $\beta$-gal) activity, cells were seeded into 24-well plates and treated with $\mathrm{BrdU}$ as before. Lysosomal content of the cells was determined using the lysosomotrophic acridine orange stain (Sigma). Cells were washed with PBS and incubated for 10 min with $5 \mu \mathrm{g} / \mathrm{ml}$ acridine orange in PBS. After four washes with PBS, cells were harvested by trypsinization and fluorescence was quantified by flow cytometry. SA- $\beta$-gal activity was determined using the ImaGene Green $\mathrm{C}_{12}$ FDG lacZ detection kit (Molecular Probes) [39] according to the manufacturer's instructions. Briefly, cells were incubated for $90 \mathrm{~min}$ with $300 \mu \mathrm{mol} / \mathrm{l}$ chloroquine in culture medium to inhibit endogenous $\beta$-galactosidase activity. After washing with PBS, cells were incubated for $3 \mathrm{~h}$ with $33 \mu \mathrm{mol} / 1 \mathrm{C}_{12} \mathrm{FDG}$, a fluorogenic substrate of $\beta$-galactosidase. After two washes with PBS, cells were resus- pended by trypsinization and fluorescence was quantified immediately by flow cytometry as above. SA- $\beta$-gal was also detected using an immunohistochemical X-gal stain (Sigma). Briefly, cells were seeded in an eight-well chamber slide and treated with BrdU as before. After 7 days, cells were fixed and stained using the kit according to the manufacturer's instructions.

\section{Statistical analysis}

All experiments were performed three times, unless otherwise stated, and the results are presented as the mean of these experiments with $95 \%$ confidence interval of the mean. Wherever indicated, significance was obtained using a two-sided Student's $t$-test.

\section{Results}

\section{5-Bromo-2-deoxyuridine activates DNA damage response pathways in A549 cells}

Both Chk1 and Chk2 proteins are transducers of DNA damage responses and lie downstream of the ATM and the ATR DNA damage sensors [40]. The ATR/Chk1 pathway has been implicated in responses to singlestrand breaks, whereas the ATM/Chk2 pathway is involved in responses to double-strand breaks, although there can be an overlap between the two pathways. Both pathways are involved in mismatch-repair responses. p53 is activated in response to various cellular stresses by phosphorylation at specific sites, depending on the upstream signal [41]. We began by examining the DNA damage response induced in BrdU-treated A549 cells. Phospho-Chk1 and phospho-p53 (Ser 15) were detected in control cells at culture day 7 (Figs 1 and 2a), indicating background DNA damage response activity, which is predictable in an aneuploid tumour cell line such as A549. Cells cultured for 7 days in BrdU-containing medium displayed increased DNA damage response activity, with increased levels of phospho-Chk1 and the induction of phospho-Chk2 (Fig. 1). Increased levels and nuclear localization of total p53, increased levels of phospho-p53 (Ser 15) and induction of phospho-p53 (Ser 37, 46) were also evident in response to BrdU treatment (Fig. 2a). An increase in the levels of total p53 was confirmed by Western blotting (Fig. 2b). Thus, several DNA damage response pathways are activated in A549 cells in response to BrdU exposure.

\section{Altered morphology of 5-bromo-2-deoxyuridine-treated cells}

BrdU induced substantial changes in the morphology of A549 cells. The incidence of binucleation, multinucleation, micronucleation and enlarged nuclei was increased in A549 cells cultured with BrdU, compared with control cells (Fig. 3a).

After 7 days of culturing, the BrdU-treated cells were enlarged and flattened and resembled senescent-like cells (Fig. 3a). Similar cells were present sporadically in 
Fig. 1

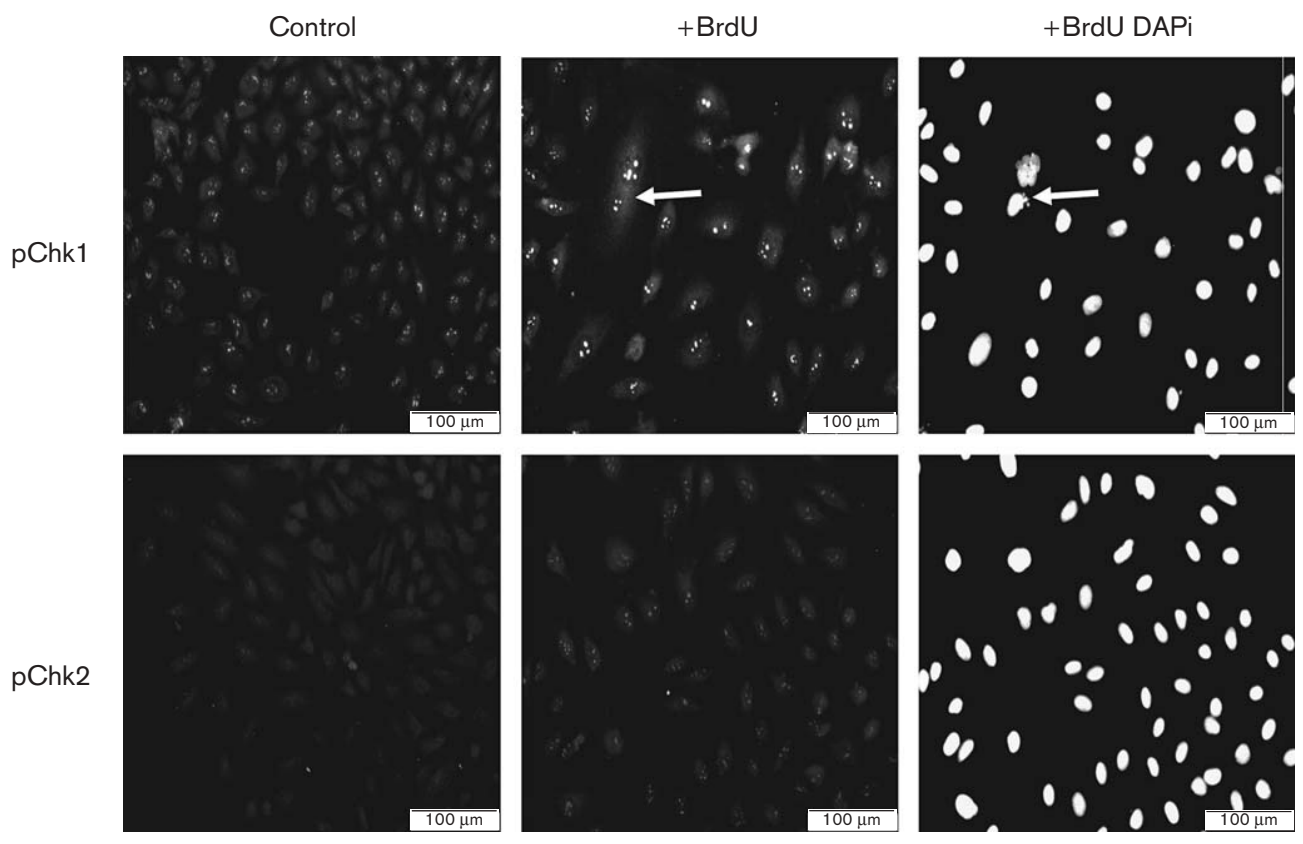

DNA damage-signalling responses in BrdU-treated cells. Phospho-Chk1 was detected in control cells (control) at day 7 of culture. Increased levels of phospho-Chk1 and induction of phospho-Chk2 occurred in response to 7 days of BrdU treatment (+BrdU). Nuclei were visualized using a DAPi counterstain (+ BrdU DAPi). Abnormal nuclear morphology is indicated with an arrow. Results represent three experimental repeats. BrdU, 5-bromo2-deoxyuridine.

control populations, but their incidence, estimated microscopically to be approximately $1 \%$, was significantly lower than in treated populations. We were interested in comparing enlarged BrdU-treated cells $\left(\mathrm{BrdU}^{\mathrm{L}}\right)$ with large cells in control populations $\left(\mathrm{Cntl}^{\mathrm{L}}\right)$ and with control and treated cells that appeared to have more normal morphologies $\left(\mathrm{Cntl}^{\mathrm{N}}\right.$ or $\mathrm{BrdU}^{\mathrm{N}}$, respectively). We therefore defined the $\mathrm{Cntl}^{\mathrm{L}}$ population as the largest $1 \%$ of the total control population, according to their forwardscatter properties by flow cytometry. We then used the same gate to analyse the treated population (Fig. 3b). Using this method, it was confirmed that the larger morphology was approximately 10 times more prevalent in treated populations $(P<0.01)$. In addition, the average size of the $\mathrm{BrdU}^{\mathrm{N}}$ cells was significantly greater $(P<0.001)$ than that of the $\mathrm{Cntl}^{\mathrm{N}}$ cells, as indicated by a shift in the forward scatter of the BrdU-treated population (Fig. 3b and c).

\section{Inhibition of cell proliferation by 5-bromo-2-deoxyuridine}

BrdU significantly inhibited proliferation of A549 cells (Fig. 3d). By day 7 of treatment, there was a $75 \%$ reduction in cell number in BrdU-treated populations compared with controls $(P<0.05)$. This reduction in cell number was not due to toxicity as the number of nonviable cells remained low during culture in both control and treated populations.

\section{Modulation of cell cycle regulatory proteins in response to 5-bromo-2-deoxyuridine}

We proceeded to determine the effects of BrdU on cell cycle regulatory proteins and to investigate the extent to which cell cycle arrest, senescence and differentiation were occurring in response to BrdU. PCNA plays an essential role both in cell proliferation and in DNA repair processes [42]. At day 1, BrdU-treated cells had increased levels of nuclear PCNA, compared with control cells (Fig. 4a). At day 7, however, BrdU-treated cells had reduced levels of PCNA, compared with control populations, with some cells also exhibiting nuclear exclusion. This might reflect initial attempts at PCNA-mediated DNA repair, followed by downregulation of PCNA during cell cycle inhibition. The reduction in PCNA expression at day 7 was confirmed by Western blotting (Fig. 4b). Cyclin D1, the $G_{1}$ initiating protein, was virtually absent in treated cells at day 7 (Fig. 5a). This, along with a reduction in phosphorylated $\mathrm{Rb}$ protein (Fig. 5b), indicates inhibition at the $G_{1}$ and $G_{1} / S$ phase transition point of the cell cycle [40].

The cyclin-dependent kinase inhibitors (CDKIs), p21, p27 and p57, function primarily as negative regulators of the cell cycle [43]. p21 plays a central role in cell cycle regulation, apoptosis and differentiation [44], and has inhibitory effects on cyclins at all phases. In control cells, the number of p21-positive cells and the levels of p21 
Fig. 2
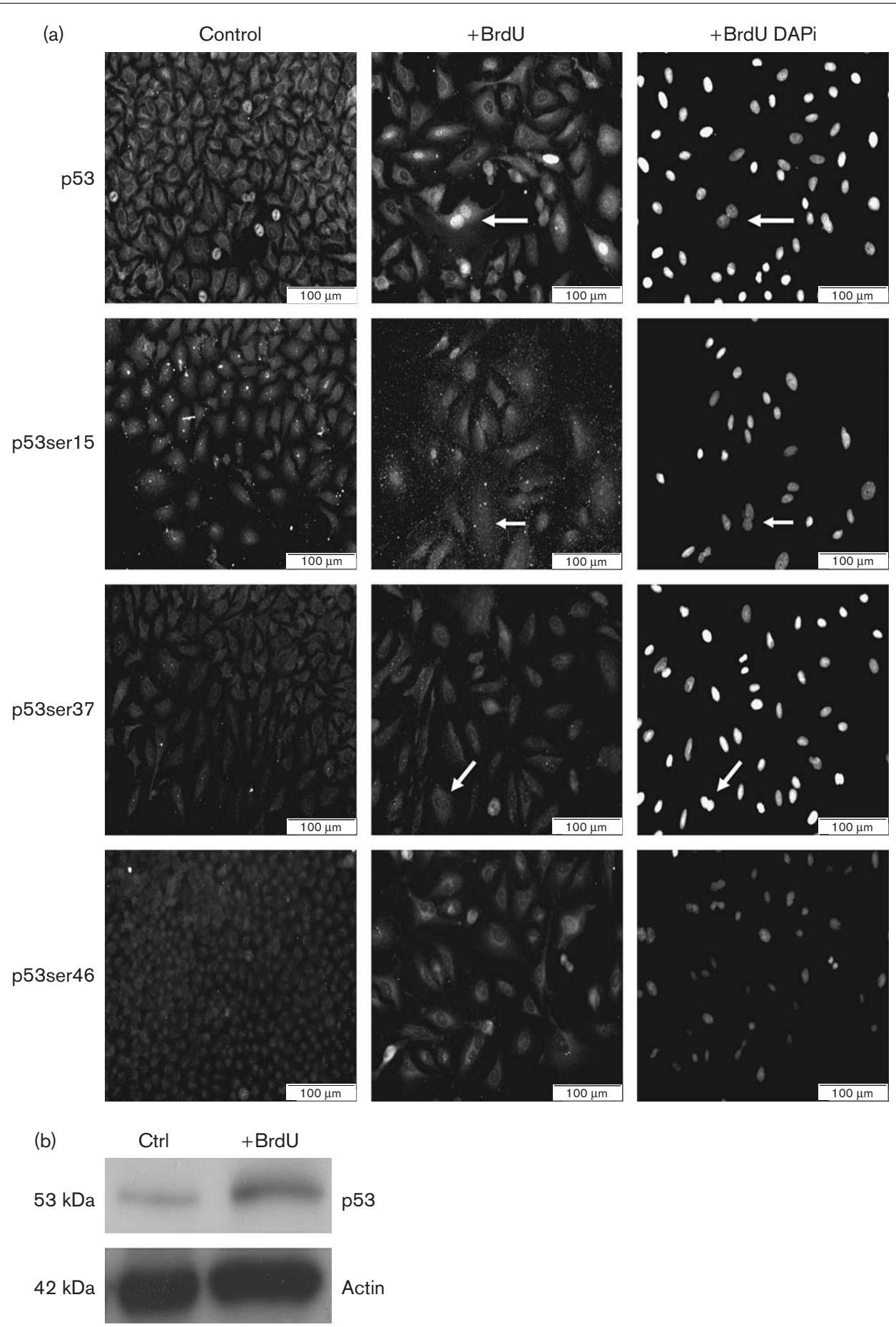

p53-signalling responses in BrdU-treated cells. (a) p53 and phospho-p53 (Ser 15) were detected in control cells (control) at day 7 of culture. Increased levels of and nuclear localization of p53 and increased levels of phospho-p53 (Ser15, 37 and 46) occurred in response to 7 days of BrdU treatment (+BrdU). (b) Increased total p53 protein levels, as detected by Western blot. Nuclei were visualized using a DAPi counterstain (+ BrdU DAPi). Binucleation is indicated with an arrow. Results represent three experimental repeats. BrdU, 5-bromo-2-deoxyuridine; Ctrl, control.

protein per cell decreased during the culture period (Fig. 6a). This very likely reflects an initial increase in p21 activity to prevent the apoptosis following trypsinization and a subsequent decrease on reattachment to permit growth in culture. In contrast, p21 activity was almost completely inhibited in BrdU-treated cells at day 1 ; thereafter, the levels increased and exceeded the levels in the control cells by day 7 (Fig. 6a and b). Even at day 7, 
Fig. 3
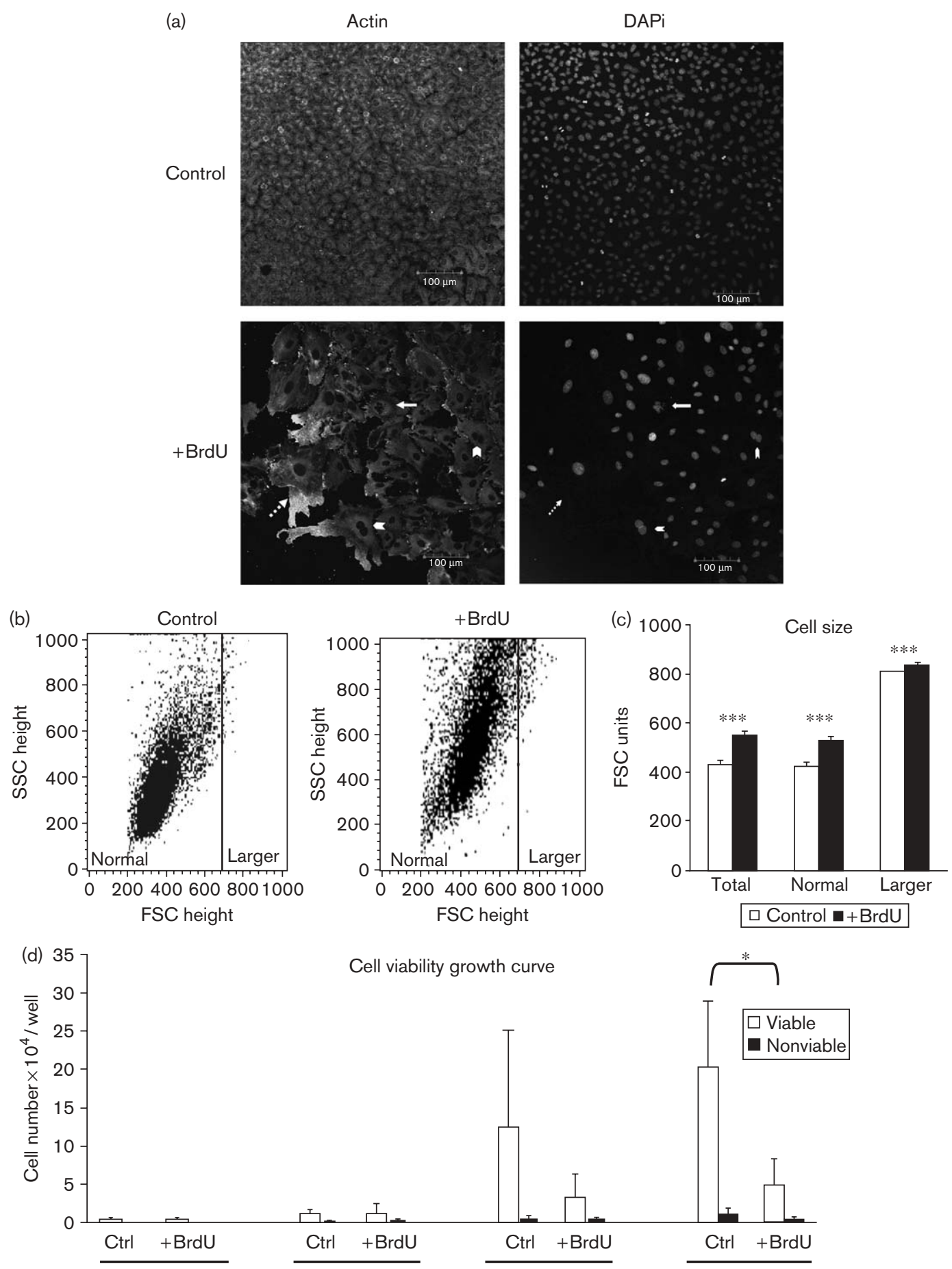

Cell viability growth curve

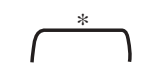

Day 1

Effects of BrdU on cell proliferation and morphology. (a) Actin immunofluorescence with DAPi counterstaining, which was visualized using confocal microscopy, indicated increased cell size (dashed line arrow), binucleation (arrowhead) and micronucleation (arrow) in populations after 7 days of BrdU treatment. (b) An overall increase in cell size was apparent in the BrdU-treated population by day 7, as indicated by a shift in forward scatter (FSC) by flow cytometry. BrdU ${ }^{\mathrm{L}}$ cells were approximately 10 times more prevalent than $\mathrm{Cnt}^{\mathrm{L}}$ cells. (c) The increase in cell size was significant in the total populations and also when 'normal' sized $\left(\mathrm{Cntl}^{\mathrm{N}}\right.$ and $\left.\mathrm{BrdU}^{\mathrm{N}}\right)$ and 'large' cells $\left(\mathrm{Cntl} \mathrm{L}^{\mathrm{L}}\right.$ and BrdU $\left.{ }^{L}\right)$ were compared, $P<0.01$ and $P<0.001$, respectively. (d) BrdU induced a significant reduction of proliferation in $A 549$ cells by day 7 of treatment $(P<0.05)$. Results represent at least three experimental repeats. BrdU, 5-bromo-2-deoxyuridine; Ctrl, control. 
Fig. 4
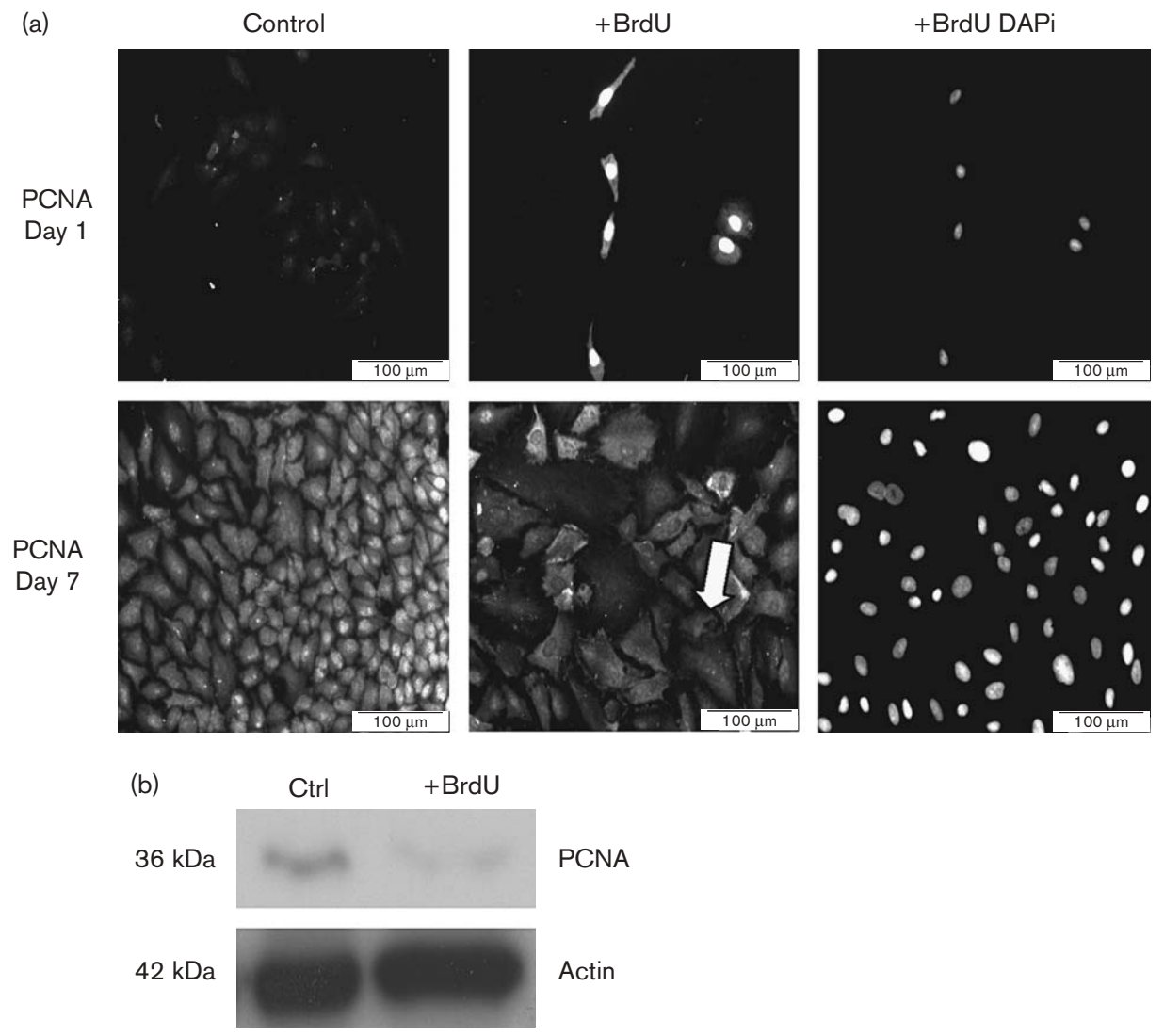

Effects of BrdU on PCNA expression. (a) Nuclear PCNA was induced at day 1 of BrdU treatment. In contrast, PCNA was absent or at low levels in control cells at this time point. Subsequently, PCNA levels increased in the control cells and decreased in the BrdU-treated cells after 7 days' treatment with BrdU. Nuclear exclusion is indicated by an arrow. (b) Reduction in PCNA protein levels following 7 days of BrdU treatment, as detected by Western blot. Results represent at least three experimental repeats. BrdU, 5-bromo-2-deoxyuridine; Ctrl, control; PCNA, proliferating cell nuclear antigen.

p21 was present in only approximately $10 \%$ of the treated cells (Fig. 6a). In contrast to p21, cells treated for 7 days with BrdU also had increased levels of nuclear p27 (Fig. 6c) and p57 (Fig. 6d), compared with control cells.

\section{5-Bromo-2-deoxyuridine activates cell cycle checkpoints}

The effects of BrdU on cell cycle progression were analysed. Ki-67 was used as a marker of actively cycling cells to allow separation of $2 \mathrm{C}$ populations into $\mathrm{G}_{0}$ and $\mathrm{G}_{1}$ phases. When total populations were examined at day 7 , control cells displayed a normal cell cycle distribution. They also displayed a larger 4C population, accounting for approximately $8 \%$ of the total population, which presumably reflected the aneuploid nature of A549 cells (Fig. 7a). In contrast, BrdU induced a significant increase in the number of cells accumulated in $G_{0}$ and $S$ phase with approximately 17 and $16 \%$ of the total BrdU population in each respective phase, compared with 2 and $7 \%$ of total control populations. A corresponding significant reduction in $2 \mathrm{C} / \mathrm{G}_{1}$ phase BrdU-treated cells was evident. This indicates that $\mathrm{BrdU}$ induced a prolonged or halted $S$ phase, which was probably due to futile cycles of repair; it also caused cells to undergo mitotic exit and to withdraw from the cell cycle into $G_{0}$. When $\mathrm{BrdU}^{\mathrm{N}}$ and $\mathrm{BrdU}^{\mathrm{L}}$, as previously defined in Fig. 3, were analysed separately, it was found that $\mathrm{BrdU}^{\mathrm{N}}$ cells predominantly accounted for the halt at $\mathrm{G}_{0}(P<0.01)$ (Fig. 7b). In contrast, approximately $40 \%$ of the $\mathrm{BrdU}^{\mathrm{L}}$ cells were evenly divided between the $S$ and the $G_{2} / M$ phases; the latter distribution had not been apparent in the analysis of the total population (Fig. 7c). Significantly more $\mathrm{BrdU}^{\mathrm{L}}$ than $\mathrm{Cntl}^{\mathrm{L}}$ cells were present in the $\mathrm{S} \quad(P<0.0001)$ and the $\mathrm{G}_{2} / \mathrm{M}$ phases $(P<0.01)$. In contrast, over $90 \%$ of $\mathrm{Cntl}^{\mathrm{L}}$ cells were halted with a greater 4C DNA content, significantly more than in corresponding $\mathrm{BrdU}^{\mathrm{L}}$ cells $(P<0.00001)$.

The cdc-2/cyclin B complex is pivotal in regulating the $\mathrm{G}_{2} / \mathrm{M}$ checkpoint [40]. Phosphorylation of cdc-2 renders it inactive. Downregulation of active cdc-2/cyclin B 
Fig. 5

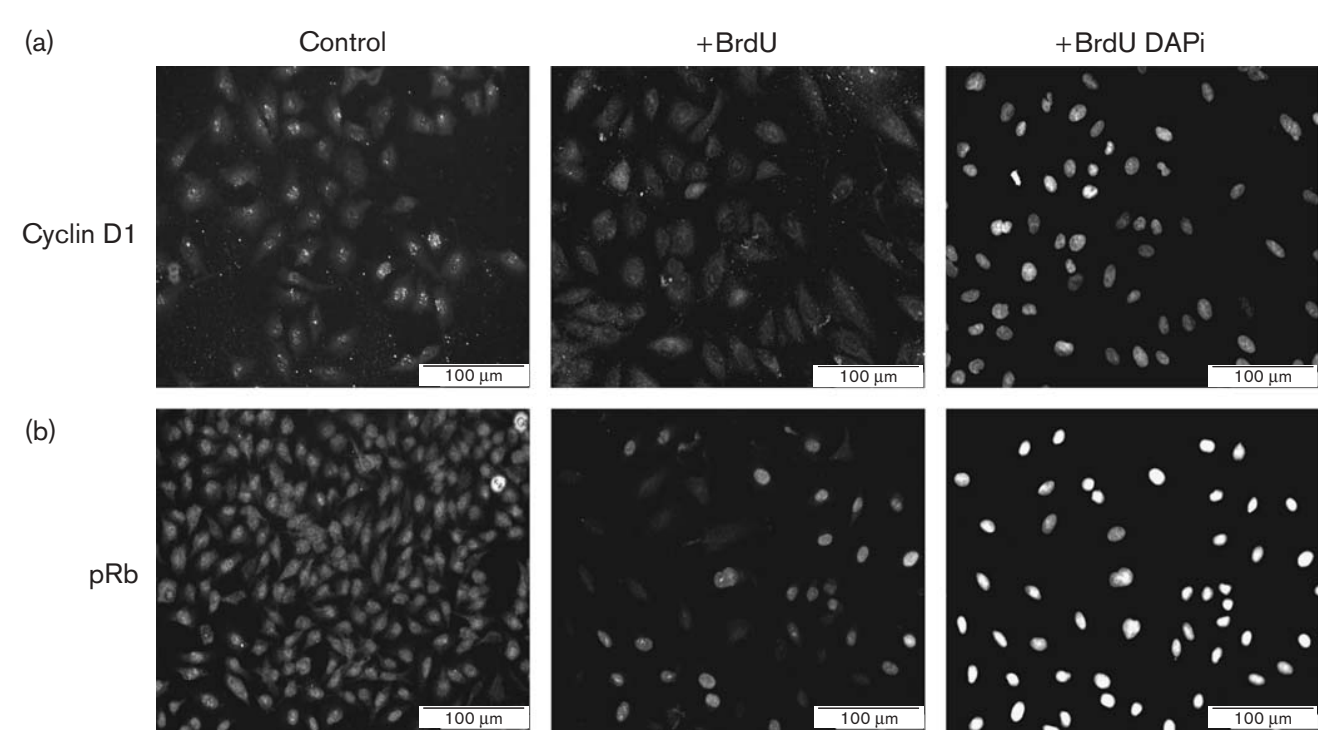

Effects of BrdU on cell cycle activators. (a) Cyclin D1 and (b) phospho-Rb expression was reduced in BrdU-treated cells by day 7 compared with control cells. Results represent at least three experimental repeats. BrdU, 5-bromo-2-deoxyuridine.

complexes is required for cytokinesis. Delayed degradation of cyclin B can lead to cytokinesis failure and mitotic catastrophe with multinucleation and multimicronucleation, and can halt it at the $\mathrm{G}_{2} / \mathrm{M}$ checkpoint $[45,46]$. Although the percentage of control and treated cells expressing cyclin $\mathrm{B}$ was similar during all the phases of the cell cycle (data not shown), the amount of cyclin B per cell was higher in treated cells, compared with control, by day 7 (Fig. 8a). Increased cyclin B expression was also associated with abnormal mitosis, both as multinucleation and enlarged nuclei, in treated cells (Fig. 8b). A slight increase in the activity of cdc-2 was also suggested by a moderate decrease in its phosphorylation levels (Fig. 8b and c). This suggests that cyclin B activity is elevated in response to BrdU-mediated DNA damage, leading to cell cycle arrest at the $\mathrm{G}_{2} / \mathrm{M}$ checkpoint. Although this would lead to cell death in normal cells, the dysregulated cell cycle machinery in A549 cells can result in the $G_{2} / \mathrm{M}$ halt and the mitotic catastrophe observed in a subpopulation of these cells.

\section{Induction of senescence-related markers in 5-bromo-2-deoxyuridine-treated cells}

A range of senescence-related markers was used to evaluate the induction of a senescence-like phenotype in A549 cells in response to BrdU.

As shown above, increased numbers of large cells with a senescent-like morphology were present in BrdU-treated A549 populations (Fig. 3b and c). Moreover, there was also an increase in average cell size in the $\mathrm{BrdU}^{\mathrm{N}}$ population, compared with $\mathrm{Cntl}^{\mathrm{N}}$ cells (Fig. 3c). When cell size was compared with cell cycle phase in total populations, it was found that BrdU-treated cells were larger than control cells at all stages of the cell cycle. Therefore, despite their increased size, BrdU-treated cells remained capable of progressing through the cell cycle and did not accumulate in any particular phase (Fig. 9a).

Analysis of side scatter revealed a significant increase in cell granularity in response to $\operatorname{BrdU}(P<0.01)$, which again was evident at all cell cycle phases (Fig. 9b). Granularity is considered to reflect an increased organellar content in senescent cells [39]. Increased lysosomal content is also associated with cellular senescence [39]. Lysosomal content was slightly increased in BrdU-treated cells, compared with control cells, at day 7 as determined by uptake of the lysosomotrophic fluorescent dye, acridine orange (Fig. 9c). Separation of $\mathrm{Cntl}^{\mathrm{N}}$ and $\mathrm{BrdU}^{\mathrm{N}}$ populations from the $\mathrm{Cntl}^{\mathrm{L}}$ and $\mathrm{BrdU}^{\mathrm{L}}$ populations predictably showed that increased lysosomal content correlated with increased cell size in both control and treated cells.

BrdU-treated cells had a higher rate of metabolic activity per cell than control cells $(P<0.01)$ (Fig. 9d). This is consistent with a senescence-like phenotype.

SA- $\beta$-gal activity was measured using two different assays. Cleavage of the $\beta$-galactosidase substrate $\mathrm{C}_{12} \mathrm{FDG}$, measured by flow cytometry, revealed a significant increase in SA- $\beta$-gal activity in BrdU-treated cells 
Fig. 6

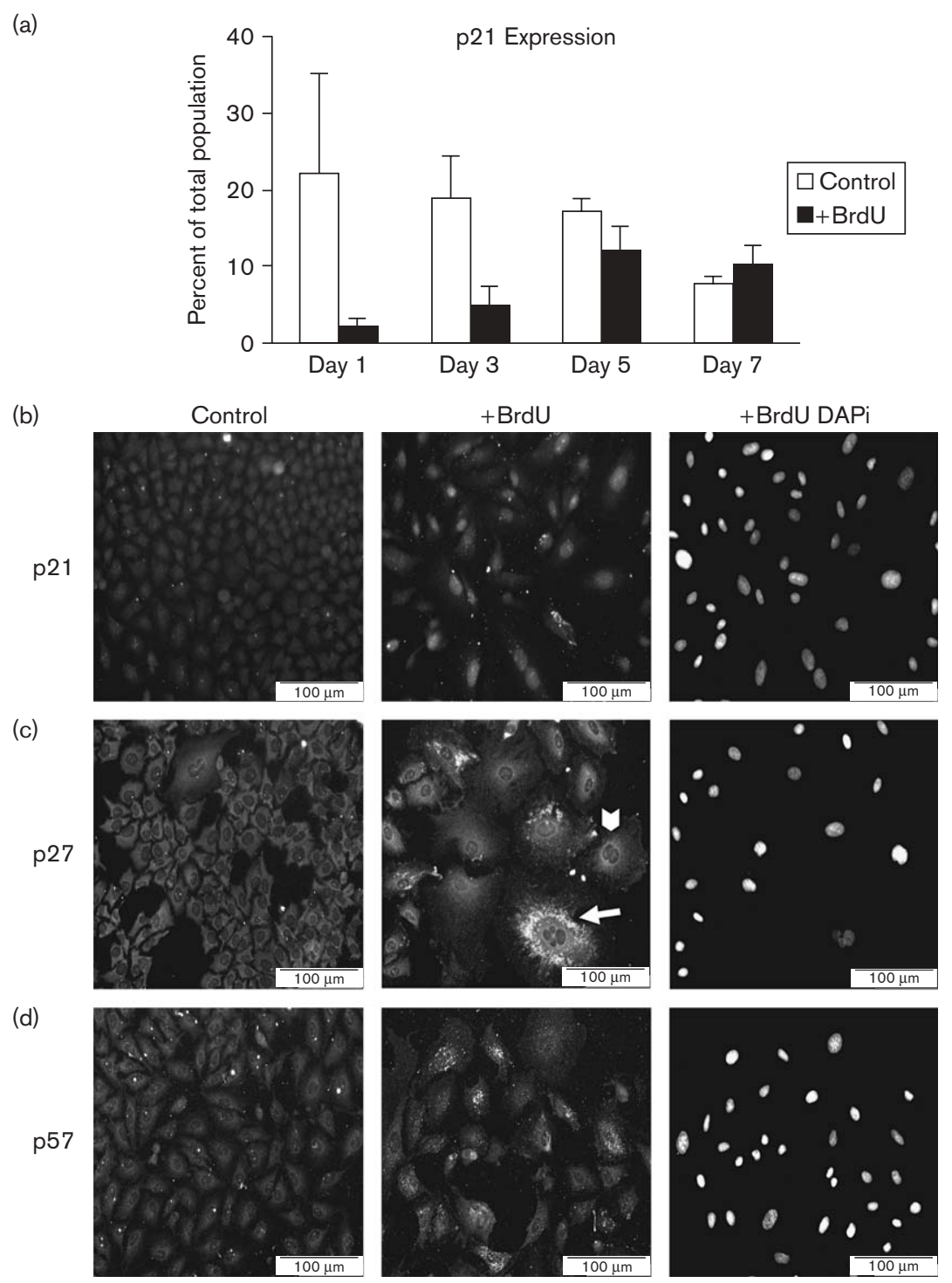

Effects of BrdU on p21, p27 and p57. (a) The number of control cells expressing p21 declined from approximately 20 to $7 \%$ during the culture period. In contrast, p21 expression was inhibited by BrdU on days 1 and 3 of the culture. Although levels rose thereafter, no more than $10 \%$ of the treated cells expressed p21. Results represent two experimental repeats. (b) p21 was weakly detectable by immunofluorescence in control cells at day 7. In contrast, nuclear localization of p21 was detected in BrdU-treated cells. (c) Cytoplasmic p27 was present in control cells throughout the culture period. Cytoplasmic localization was evident and levels of expression were higher than in control populations, particularly in cells with abnormal nuclei, by day 7. Binucleate cells are indicated by arrowheads and micronucleation indicated by arrows. (d) Low levels of cytoplasmic p57 were present in control cells throughout the culture period. p57 localization became cytoplasmic and a 'speckled' immunostaining pattern (arrow) over time in culture with BrdU was evident after 7 days. Results represent three experimental repeats. BrdU, 5-bromo-2-deoxyuridine.

$(P<0.01)$ (Fig. 10a). Staining of cells for SA- $\beta$-gal using an $\mathrm{X}$-gal substrate confirmed the increase in SA- $\beta$-gal activity in response to BrdU (Fig. 10b).

Thus, per cell, BrdU-treated cells were larger, more granular, had increased lysosomal content, were more metabolically active and displayed more SA- $\beta$-gal activity than their control counterparts; all these features indicate the induction of a senescence-like phenotype.

\section{Effects of 5-bromo-2-deoxyuridine on cell differentiation}

It has previously been reported that $\mathrm{BrdU}$ modulates the expression of differentiation-related proteins such as cytokeratins, which can be induced or upregulated in lung cancer cell lines, depending on the endogenous expression levels [23]. We investigated whether BrdUmediated upregulation of cytokeratin expression in A549 cells was cell cycle dependent. If so, this might reflect a 
Fig. 7
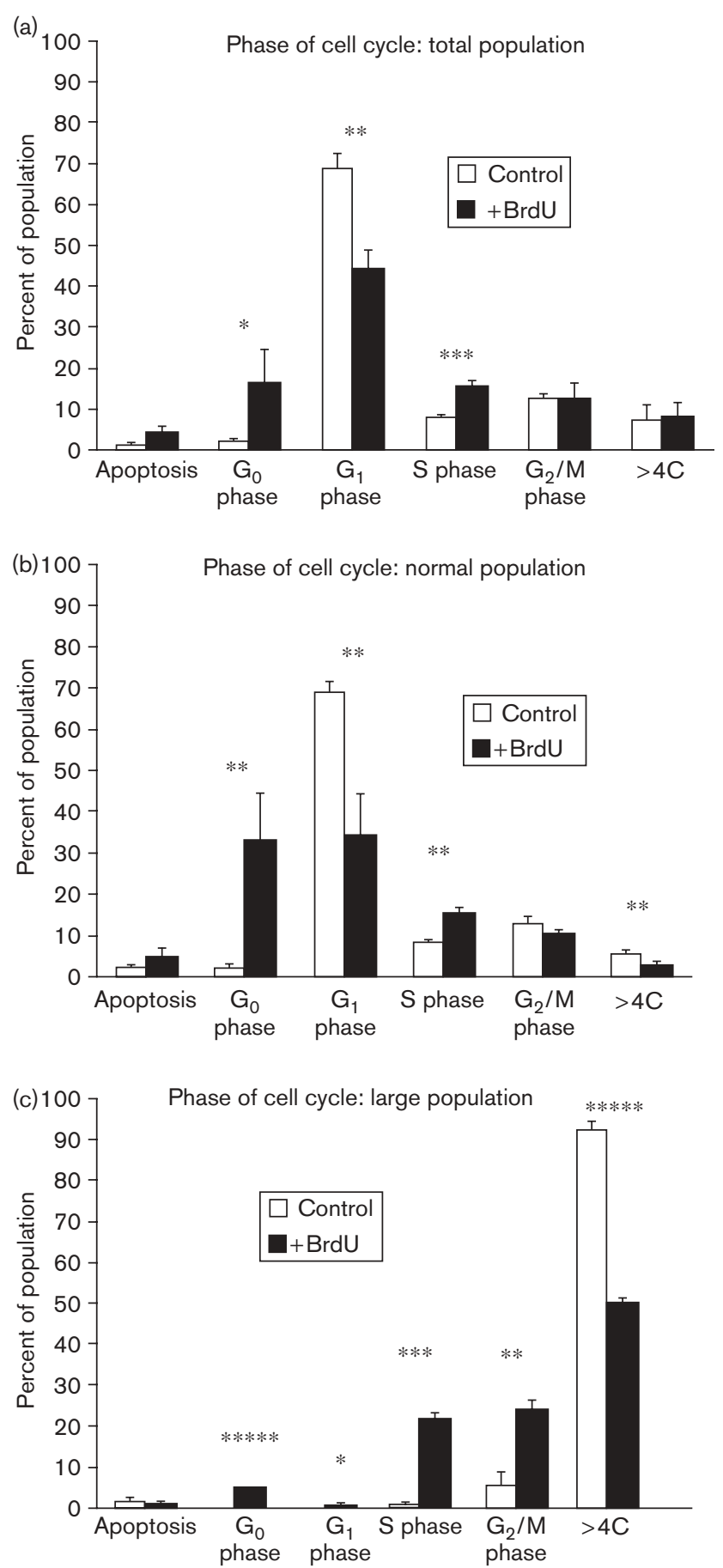

Activation of cell cycle checkpoints. (a) Analysis of total populations showed that control cells had a normal cell cycle distribution, whereas BrdU treatment induced accumulations of cells at $G_{0}$ and $S$ phases, and a reduction of cells in $\mathrm{G}_{1}$. Separate analysis of (b) $\mathrm{Cntl}^{\mathrm{N}}$ and BrdU ${ }^{\mathrm{N}}$ and (c) $\mathrm{Cntl} \mathrm{L}^{\mathrm{L}}$ and $\mathrm{BrdU}^{\mathrm{L}}$ populations revealed that $\mathrm{BrdU}^{\mathrm{N}}$ cells accounted for most of the BrdU-treated cells in $\mathrm{G}_{0}$; $\mathrm{BrdU}^{\mathrm{L}}$ cells were halted at $S$ and $G_{2} / M$ phases and had a greater $4 \mathrm{C}$ DNA content, whereas most control cells were halted with greater 4C DNA content. Results represent at least three experimental repeats. BrdU, 5-bromo-2deoxyuridine. differentiation-related halt in the cell cycle. One hundred percent of the control and the BrdU-treated cells expressed cytokeratins (results not shown). Cytokeratin expression, however, was significantly upregulated in all treated cells during all the phases of the cell cycle $(P<0.01)$, with no accumulation occurring in any one phase (Fig. 11).

\section{Discussion}

The ability of BrdU to both induce DNA damage and modulate the cell phenotype has long been recognized. The molecular mechanisms associated with these effects, however, are unknown and potential links between the two processes have not been explored. Furthermore, the question of whether $\mathrm{BrdU}$ induces differentiation or senescence requires clarification. We have examined the effects of BrdU on DNA damage response and cell cycle checkpoint pathways, and the related impacts on cell cycle progression and cell phenotype in a lung cancer cell line. BrdU-induced DNA damage occurs during several cell cycle phases. The 'multihit' nature of BrdU-induced DNA damage led us to examine unsynchronized cell populations, thus enabling us to examine the ensemble of BrdU effects. Our studies show that A549 cells respond to BrdU-induced DNA damage by upregulating background Chk1 responses, activating Chk2 and phosphorylating p53. Activation of the DNA-repair function of PCNA is also suggested by the early upregulation of this protein after exposure to BrdU. A decoupling of normal DNA damage signalling and cell cycle checkpoint activation in these transformed cells leads to a deregulated mitosis with an increase in the incidence of abnormal nuclei and accumulation of cells in $\mathrm{G}_{0}, \mathrm{~S}$ and $\mathrm{G}_{2} / \mathrm{M}$ phases of the cell cycle. An increase in average cell size occurs and phenotypic changes consistent with senescence are apparent (summarized in Fig. 12).

Our findings thus support the contention that BrdU induces a senescence-like phenotype in cancer cells. Senescence is a mechanism to suppress inappropriate proliferation, e.g. that follows DNA damage; it is defined as an irreversible halt in cell cycle when cells become unresponsive to mitogenic or apoptotic signals [27]. Senescent cells are enlarged and have increased granularity; nevertheless, they remain viable and metabolically active [47]. In this study, the A549 populations that appeared morphologically normal were termed $\mathrm{Cntl}^{\mathrm{N}}$ and $\mathrm{BrdU}^{\mathrm{N}}$. The majority of both of these populations had a 2G DNA content. Unlike the $\mathrm{Cntl}^{\mathrm{N}}$ population, however, approximately one-third of the $\mathrm{BrdU}^{\mathrm{N}}$ population had withdrawn from the cell cycle and was halted at $G_{0}$ (Fig. 7b). The $\mathrm{BrdU}^{\mathrm{N}}$ cells were also slightly larger than their $\mathrm{Cntl}^{\mathrm{N}}$ counterparts (Fig. 3d) and senescentassociated features were increased in the BrdU-treated 2C population (Fig. 9). Despite their more 'normal' 
Fig. 8

(a)

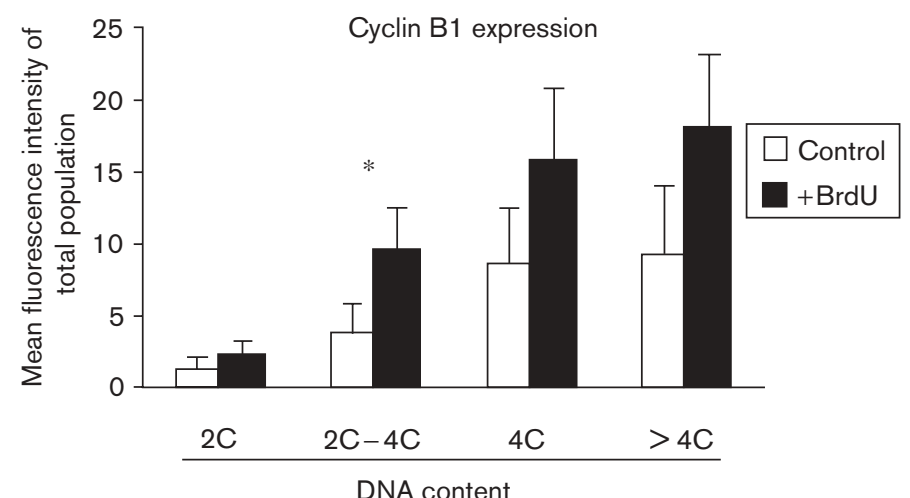

(b)
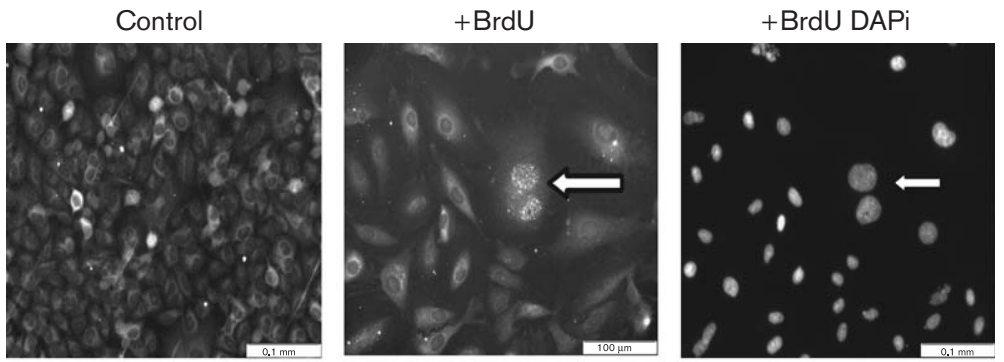

Cyclin B1
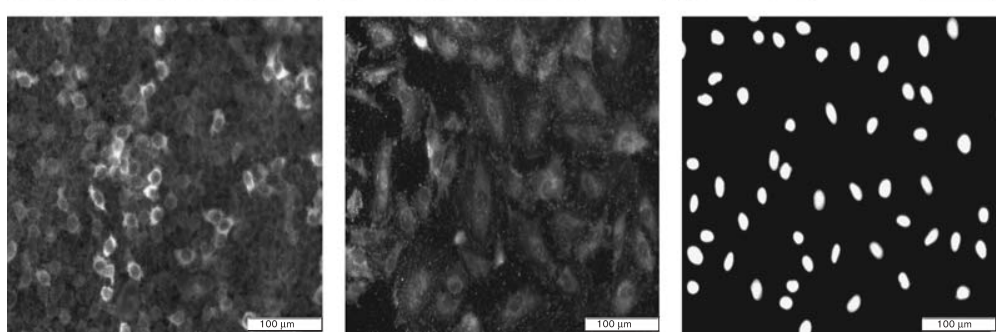

(c)

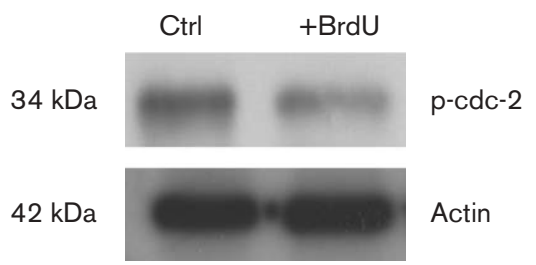

(a) Cyclin B1 levels were increased in BrdU-treated cells at each phase of the cell cycle compared with control populations. (b) Increased levels of nuclear cyclin B1 were frequently evident in BrdU-treated cells containing enlarged or binuclei (arrow) (day 7). A slight decrease in the levels of phosphorylated cdc-2 was evident in BrdU-treated cells (day 7). (c) Western blot confirmation of decreased levels of phospho-cdc-2. Results represent three experimental repeats. BrdU, 5-bromo-2-deoxyuridine; Ctrl, control.

morphological appearance, therefore, the $\mathrm{BrdU}^{\mathrm{N}}$ population had several senescent-like characteristics. It seems likely that BrdU-induced DNA damage caused these cells to arrest, in this case mainly at $G_{0}$. The result of this arrest was the induction of a senescence-like phenotype rather than apoptosis.

Unlike the $\mathrm{Cntl}^{\mathrm{N}}$ population, the enlarged $\mathrm{Cntl}^{\mathrm{L}}$ population, by definition, possessed senescent-like features. The $\mathrm{Cntl}^{\mathrm{L}}$ population, which represented only $1 \%$ of the total control population, had increased cell sizes and almost exclusively a greater 4C DNA content. These cells probably reflected ongoing, spontaneous senescence due to aneuploidy and in-vitro culture conditions in the control population. In contrast, the incidence of enlarged senescent-like cells was increased 10-fold in the presence of BrdU. Unlike the $\mathrm{Cntl}^{\mathrm{L}}$ population, approximately $50 \%$ of $\mathrm{BrdU}^{\mathrm{L}}$ cells were accumulated in the $S$ and $\mathrm{G}_{2} / \mathrm{M}$ phases, indicating that they were halted at the DNA damage checkpoints. Originally defined by their regulatory role in cell cycle progression, it is now clear that DNA damage checkpoints are also involved in the 
Fig. 9

(a)

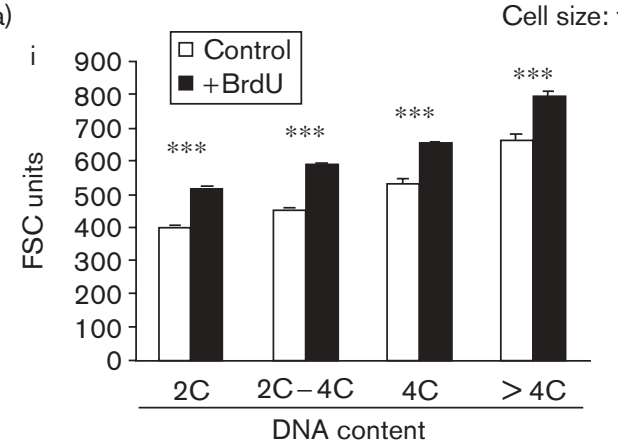

ii

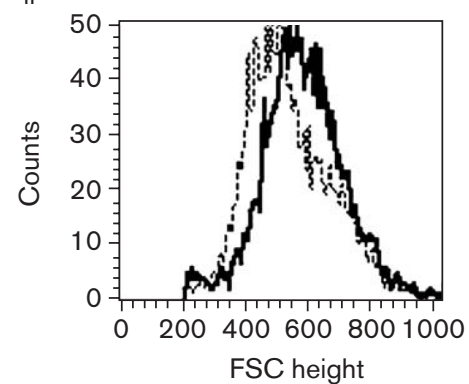

(b)

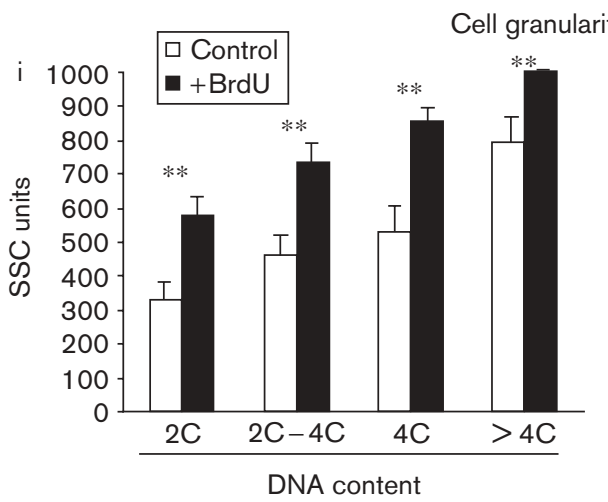

total population

ii

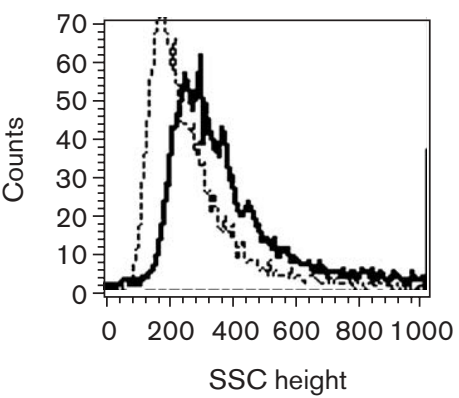

(c)

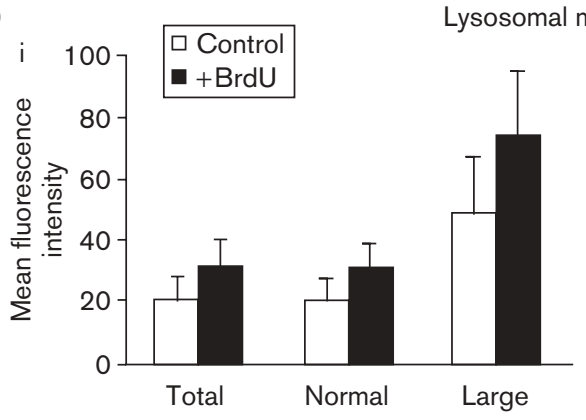

: acridine orange

ii

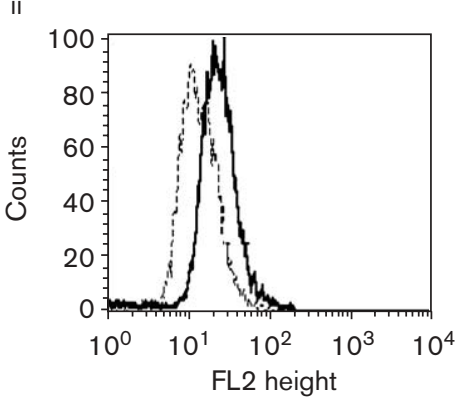

(d)

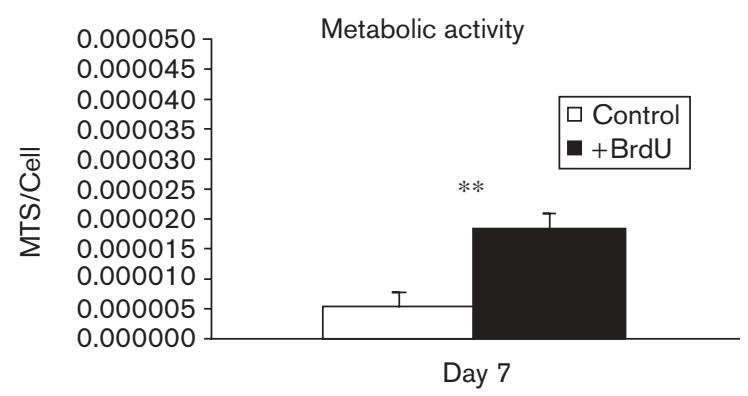

Induction of a senescence-like morphology in BrdU-treated cells at day 7. (a) (i) BrdU-treated cells were significantly larger than control counterparts during each phase of the cell cycle. (ii) A representative flow-cytometry histogram of increased cell size, as detected by forward scatter (FSC) units. (b) (i) Treated cells were also more granular than control cells at each cell cycle phase. (ii) A representative flow cytometry histogram of increased cell granularity as detected by side scatter (SSC) units. (c) (i) BrdU treatment induced increased lysosomal content in cells with both normal and large morphology. (ii) a representative flow-cytometry histogram of increased lysosomal mass. (d) BrdU-treated cells were more metabolically active than control cells. Control population: dotted line; BrdU-treated population: full line. Results represent three experimental repeats. BrdU, 5-bromo-2deoxyuridine. 
Fig. 10

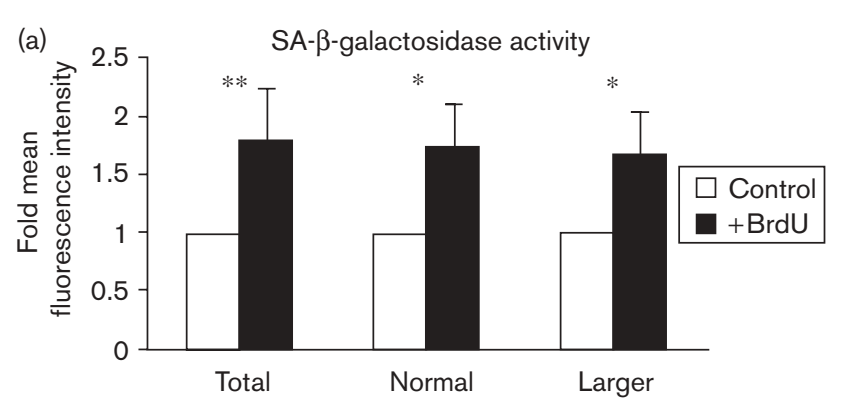

(b)

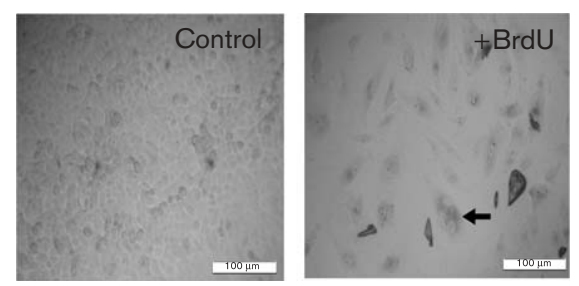

Induction of senescence-associated (SA)- $\beta$-galactosidase activity in BrdU-treated cells. (a) SA- $\beta$-galactosidase activity was significantly increased in all BrdU-treated cells, regardless of size, as determined by flow cytometry using a fluorescent $\beta$-galactosidase substrate. (b) An Xgal substrate that produces a visible stain confirmed increased levels of SA- $\beta$-galactosidase after 7 days of BrdU treatment. Results represent three experimental repeats. BrdU, 5-bromo-2-deoxyuridine.

Fig. 11

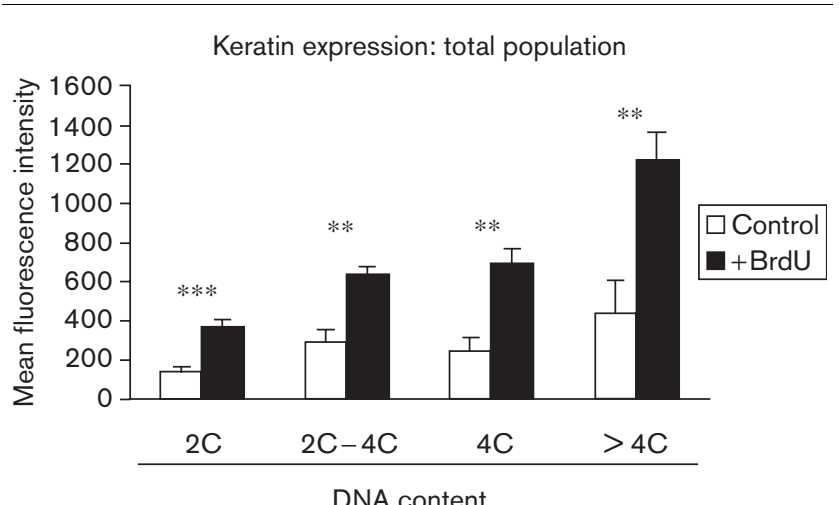

Effect of BrdU cytokeratin expression. Cytokeratin expression was increased in all BrdU-treated cells, regardless of cell size and phase of cell cycle. Results represent three experimental repeats. BrdU, 5-bromo-2-deoxyuridine.

induction and maintenance of senescence $[37,38,48]$. We therefore believe, first, that the previously reported changes in gene expression and phenotype in BrdUtreated tumour cells now seem to reflect the acquisition of senescent-like phenotypes. Second, the activation of the checkpoints in the A549 senescent-like cells in this study provides evidence that these phenotypic changes are due to BrdU-induced DNA damage responses, rather than to mutations or to alterations in methylation or to altered protein interactions in BrdU-containing DNA.
Although BrdU-induced morphological changes in A549 cells are consistent with the induction of a senescencelike phenotype, the typical gene-expression profile for senescence is not evident. Senescent normal human fibroblasts typically overexpress p21, p16 and cyclin D1. This was not the case in the present study [49]. Treatment-induced senescence of tumour cells can, however, occur in the absence of p53, p21 and p16 $[38,50]$. The mechanisms underlying senescence in both normal and tumour cells thus remain unclear. p21 is a common mediator of p53-induced cell cycle arrest [43]. Downregulation of p21, however, occurred as an early response to $\mathrm{BrdU}$ treatment, probably to avoid the inactivation of the DNA repair function of PCNA [51], indicating that the subsequent $\mathrm{G}_{0}, \mathrm{~S}$ and $\mathrm{G}_{2} / \mathrm{M}$ checkpoints activated by $\mathrm{BrdU}$ might be $\mathrm{p} 21$-independent. Downregulation of p21 and the absence of p16 in A549 cells suggest that cell cycle arrest is mediated by $\mathrm{p} 27$ and/or p57, both of which are upregulated during BrdU treatment.

The mechanisms by which cell cycle arrest is linked to senescence are also unknown; although, p27 might play a key role in linking the two processes. p27 induces cell cycle arrest during several cell cycle phases usually in response to external signals such as transforming growth factor- $\beta$ and contact inhibition [44]. Its expression, therefore, correlates with differentiation status in normal and cancer cells [52]. p57 is also involved in differentiation and plays a role in alveolar development [53]. Both p27 and p57 are also involved in senescence [54]. The overexpression of p27 can lead to an increase in cell size, protein content and metabolic activity, similar to the BrdU-mediated effects seen in this study $[55,56]$. Upregulation of p27 to p57 may explain the appearance of a senescence-like phenotype in BrdU-treated A549 cells in the absence of p21 and p16, which are usually associated with senescence induction and maintenance [47]. p27 and/or p57 could be responsible for most of the cell cycle and phenotypic changes that occur in the A549 cells following BrdU-induced damage. The mitotic exit and accumulation of $\mathrm{G}_{0}$ A549 cells following treatment could be due to a p27/p57-induced differentiation-related or senescence-related entry directly into $G_{0}$, or to a p27/ p57-induced prolonged $G_{1}$ halt, which leads to entry into $\mathrm{G}_{0}$, or both. Increased cytokeratin protein could result from an altered differentiation programme, terminal differentiation, a senescence-related programme or merely from an increase in cell size and accompanying protein expression: all these can result from increased p27/p57 activity.

It seems most likely that the altered phenotypes present in BrdU-treated populations arise after sublethal DNA damage responses. These responses, rather than leading to apoptosis result in BrdU-specific cell cycle perturbations, and the activation of regulators involved in cell 


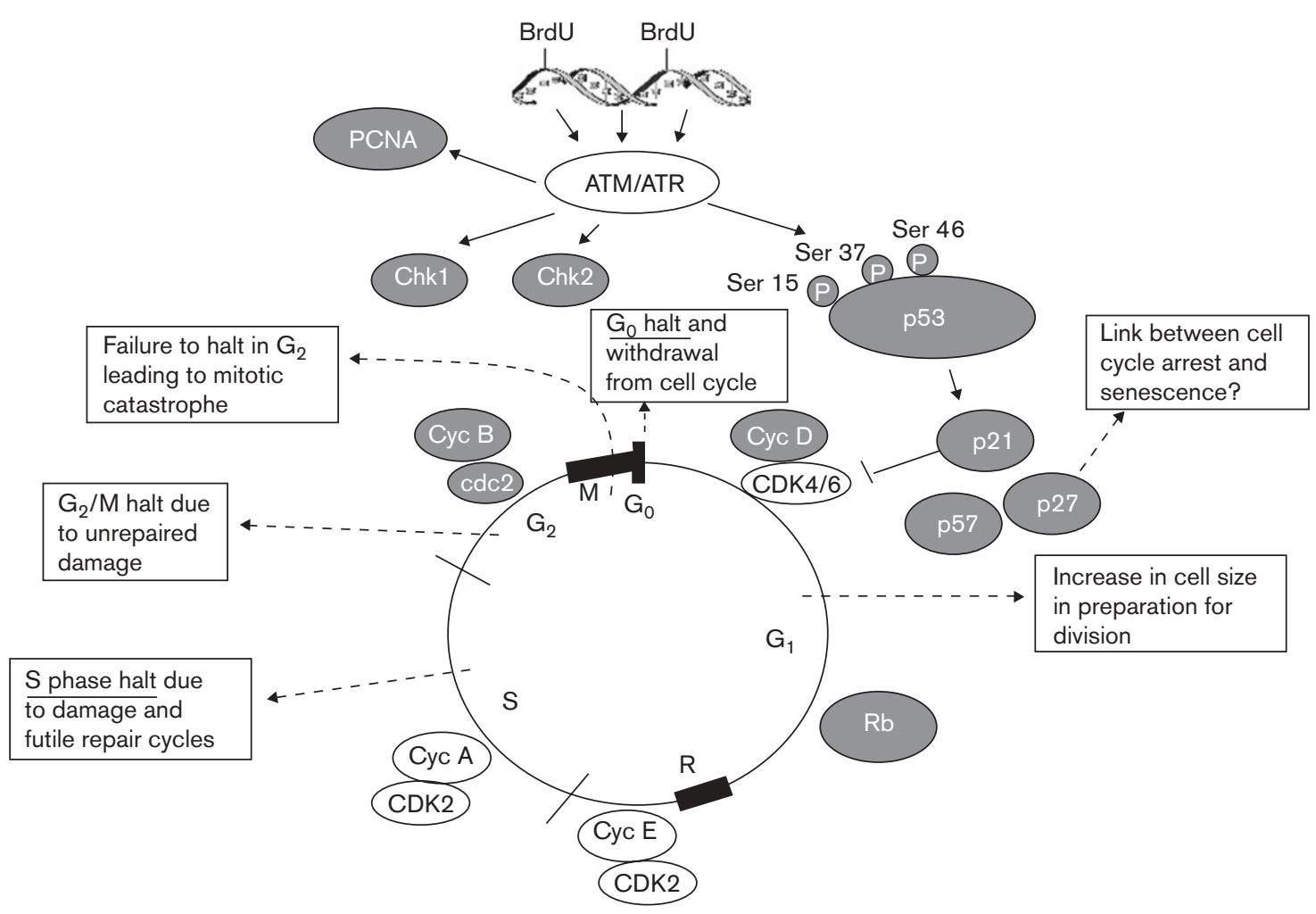

Summary of the BrdU mechanism of action in A549 cells. Proteins modulated by BrdU in this study are shown in 'grey fill'. DNA-damage checkpoints activated by BrdU (dashed arrows) and proposed implications for the cell cycle (boxes) are indicated. BrdU, 5-bromo-2-deoxyuridine; PCNA, proliferating cell nuclear antigen; Cyc, cyclin; CDK, cyclin-dependent kinase.

cycle arrest, differentiation and senescence. A precise definition of these phenotypes as being either differentiated or senescent might not be possible. Instead, we suggest that these cells have a BrdU DNA damageinduced altered phenotype that is dependent on their genotype. Rather than a BrdU-specific effect such as altered transcription factor binding to BrdU-substituted DNA, p27-mediated/p57-mediated DNA damage responses (which involve mitotic exit and other cell cycle halts) might, therefore, cause the phenotypic changes observed in BrdU-treated A549 cells. It is possible that the phenotypic changes observed in the other cell types could also be explained by any, or a combination, of these p27-mediated/p57-mediated processes.

The mechanisms by which BrdU induces various types of DNA damage have been studied sporadically since this thymidine analogue had first been designed as an anticancer agent. Similarly, the effects of BrdU on cell morphology and phenotype have been recognized but unexplained for decades. These two aspects of BrdU biology have remained relatively separate till date. We suggest that there is very likely a connection between the two. We provide evidence here that BrdU-mediated effects on cell phenotype might be due, at least in part, to
BrdU-induced DNA damage and to the subsequent perturbation of the cell cycle. As a result, phenotypic response will vary between cell types, depending on their respective DNA damage response and cell cycle machinery. DNA damage-induced cell cycle perturbations can lead to changes in gene expression that might resemble differentiation or senescence. The latter remains poorly understood, particularly in tumour cells [50]. Thus, apparent cell-specific BrdU responses, particularly in tumour cells that have abnormal and varying genotypes, might reflect cell-specific DNA damage responses, rather than BrdU-specific effects per se, such as altered transcription factor binding to BrdU-containing DNA. The ability of BrdU to modulate the cell cycle has implications for its use in cell-proliferation assays in vitro and in vivo. It also remains to be demonstrated whether BrdU induces senescence in vivo when used during chemotherapy. If so, is senescence beneficial or detrimental in this situation? Furthermore, other base analogues that are used more commonly than BrdU for cancer treatment might also have similar effects.

\section{Acknowledgement}

These studies were funded by Science Foundation Ireland. 


\section{References}

1 Djordjevic B, Szybalski W. Genetics of human cell lines. III. Incorporation of 5-bromo- and 5-iododeoxyuridine into the deoxyribonucleic acid of human cells and its effect on radiation sensitivity. J Exp Med 1960; 112:509-531.

2 Greer S. Studies on ultraviolet irradiation of Escherichia coli containing 5-bromouracil in its DNA. J Gen Microbiol 1960; 22:618-634.

3 Ribas M, Korenberg JR, Peretti D, Pichiri G, Stockert JC, Gosalvez J, et al. Sister chromatid differentiation in 5-bromo-2'-deoxyuridine-substituted chromosomes: a study with DNA-specific ligands and monoclonal antibody to histone H2B. Chromosome Res $1994 ; 2: 428-438$.

4 Prados MD, Seiferheld W, Sandler HM, Buckner JC, Phillips T, Schultz C, et al. Phase III randomized study of radiotherapy plus procarbazine, lomustine, and vincristine with or without BUdR for treatment of anaplastic astrocytoma: final report of RTOG 9404. Int J Radiat Oncol Biol Phys 2004; 58:1147-1152.

5 Anisimov VN. The sole DNA damage induced by bromodeoxyuridine is sufficient for initiation of both aging and carcinogenesis in vivo. Ann N Y Acad Sci 1994; 719:494-501.

6 Arlt MF, Casper AM, Glover TW. Common fragile sites. Cytogenet Genome Res 2003; 100:92-100.

7 Hsu TC, Somers CE. Effect of 5-bromodeoxyuridine on mammalian chromosomes. Proc Natl Acad Sci U S A 1961; 47:396-403.

8 Wojcik A, von Sonntag C, Obe G. Application of the biotin-dUTP chromosome labelling technique to study the role of 5-bromo-2' deoxyuridine in the formation of UV-induced sister chromatid exchanges in CHO cells. J Photochem Photobiol B 2003; 69:139-144.

9 Sato S, Takizawa H, Inui N. Mouse strain differences in induction of micronuclei by base analogues and nucleosides. Mutat Res 1993; 301: 45-49.

10 Call KM, Thilly WG. 5-Azacytidine inhibits the induction of transient TKdeficient cells by 5 -bromodeoxyuridine. A novel hypothesis for the facilitation of hypermethylation by 5-bromodeoxyuridine. Mutat Res 1991; 248: 101-114.

11 Hsu TC, Somers CE. Properties of $L$ cells resistant to 5-bromodeoxyuridine. Exp Cell Res 1962; 26:404-410.

12 Berry SE, Davis TW, Schupp JE, Hwang HS, de Wind N, Kinsella TJ. Selective radiosensitization of drug-resistant MutS homologue-2 (MSH2) mismatch repair-deficient cells by halogenated thymidine (dThd) analogues: Msh2 mediates dThd analogue DNA levels and the differential cytotoxicity and cell-cycle effects of the dThd analogues and 6-thioguanine. Cancer Res 2000; 60:5773-5780.

13 Berry SE, Loh T, Yan T, Kinsella TJ. Role of MutSalpha in the recognition of iododeoxyuridine in DNA. Cancer Res 2003; 63:5490-5495.

14 Littlefield JW, Gould EA. The toxic effect of 5-bromodeoxyuridine on cultured epithelial cells. J Biol Chem 1960; 235:1129-1133.

15 Abbott J, Holtzer $\mathrm{H}$. The loss of phenotypic traits by differentiated cells, $\mathrm{V}$. The effect of 5-bromodeoxyuridine on cloned chondrocytes. Proc Natl Acad Sci U S A 1968; 59:1144-1151.

16 Couwenhoven RI, Schwartz SA, Snead ML. Arrest of amelogenin transcriptional activation in bromodeoxyuridine-treated developing mouse molars in vitro. J Craniofac Genet Dev Biol 1993; 13:259-269.

17 Comi P, Ottolenghi S, Giglioni B, Migliaccio G, Migliaccio AR, Bassano E, et al. Bromodeoxyuridine treatment of normal adult erythroid colonies: an in-vitro model for reactivation of human fetal globin genes. Blood 1986; 68:1036-1041.

18 Githens S, Pictet R, Phelps P, Rutter WJ. 5-bromodeoxyuridine may alter the differentiative program of the embryonic pancreas. J Cell Biol 1976; 71:341-356.

19 Tapscott SJ, Lassar AB, Davis RL, Weintraub H. 5-bromo-2'-deoxyuridine blocks myogenesis by extinguishing expression of MyoD1. Science 1989; 245:532-536.

20 Younkin L, Silberberg D. Myelination in developing cultured newborn rat cerebellum inhibited by 5-bromodeoxyuridine. Exp Cell Res 1973; 76: 455-458.

21 Gilchrist AJ, Meuser R, Turchinsky J, Shaw AR, Pasdar M, Dixon WT. Cell adhesion-mediated transformation of a human SCLC cell line is associated with the development of a normal phenotype. Exp Cell Res 2002; 276: 63-78.

22 Feyles V, Sikora LK, McGarry RC, Jerry LM. Effects of retinoic acid and bromodeoxyuridine on human melanoma-associated antigen expression in small cell lung carcinoma cells. Oncology 1991; 48:58-64.

23 McBride S, Walsh D, Meleady P, Daly N, Clynes M. Bromodeoxyuridine induces keratin protein synthesis at a posttranscriptional level in human lung tumour cell lines. Differentiation 1999; 64:185-193.

24 Yen A, Forbes ME. c-myc down regulation and precommitment in HL-60 cells due to bromodeoxyuridine. Cancer Res 1990; 50:1411-1420.
25 Michishita E, Nakabayashi K, Suzuki T, Kaul SC, Ogino H, Fujii M, et al. 5 -Bromodeoxyuridine induces senescence-like phenomena in mammalian cells regardless of cell type or species. J Biochem (Tokyo) 1999; 126:1052-1059.

26 Minagawa S, Nakabayashi K, Fujii M, Scherer SW, Ayusawa D. Early BrdUresponsive genes constitute a novel class of senescence-associated genes in human cells. Exp Cell Res 2005; 304:552-558.

27 Campisi J. Cellular senescence as a tumor-suppressor mechanism. Trends Cell Biol 2001; 11:S27-S31.

28 Lin S, Lin D, Riggs AD. Histones bind more tightly to bromodeoxyuridinesubstituted DNA than to normal DNA. Nucleic Acids Res 1976; 3: 2183-2191.

29 Fasy TM, Cullen BR, Luk D, Bick MD. Studies on the enhanced interaction of halodeoxyuridine-substituted DNAs with $\mathrm{H} 1$ histones and other polypeptides. J Biol Chem 1980; 255:1380-1387.

30 Bick MD, Devine EA. Interaction of chromosomal proteins with BrdU substituted DNA as determined by chromatin-DNA competition. Nucleic Acids Res 1977; 4:3687-3700.

31 Schwartz SA, Snead ML. Bromodeoxyuridine-DNA interactions associated with arrest of rat odontogenesis in vitro. Arch Oral Biol 1982; 27: 9-12.

32 Satou W, Suzuki T, Noguchi T, Ogino H, Fujii M, Ayusawa D. AT-hook proteins stimulate induction of senescence markers triggered by 5-bromodeoxyuridine in mammalian cells. Exp Gerontol 2004; 39: 173-179.

33 Suzuki T, Michishita E, Ogino H, Fujii M, Ayusawa D. Synergistic induction of the senescence-associated genes by 5-bromodeoxyuridine and AT-binding ligands in HeLa cells. Exp Cell Res 2002; 276:174-184.

34 Kataoka M, Wiehle S, Spitz F, Schumacher G, Roth JA, Cristiano RJ. Down-regulation of bcl-2 is associated with p16INK4-mediated apoptosis in non-small cell lung cancer cells. Oncogene 2000; 19:1589-1595.

35 Isaka T, Nestor AL, Takada T, Allison DC. Chromosomal variations within aneuploid cancer lines. J Histochem Cytochem 2003; 51: 1343-1353.

36 Croce MV, Colussi AG, Price MR, Segal-Eiras A. Identification and characterization of different subpopulations in a human lung adenocarcinoma cell line (A549). Pathol Oncol Res 1999; 5:197-204.

37 Di Micco R, Fumagalli M, Cicalese A, Piccinin S, Gasparini P, Luise C, et al. Oncogene-induced senescence is a DNA damage response triggered by DNA hyper-replication. Nature 2006; 444:638-642.

38 Bartkova J, Rezaei N, Liontos M, Karakaidos P, Kletsas D, Issaeva N, et al. Oncogene-induced senescence is part of the tumorigenesis barrier imposed by DNA damage checkpoints. Nature 2006; 444:633-637.

39 Kurz DJ, Decary S, Hong Y, Erusalimsky JD. Senescence-associated (beta)galactosidase reflects an increase in lysosomal mass during replicative ageing of human endothelial cells. J Cell Sci 2000; 113 (Pt 20): 3613-3622.

40 Sancar A, Lindsey-Boltz LA, Unsal-Kacmaz K, Linn S. Molecular mechanisms of mammalian DNA repair and the DNA damage checkpoints. Annu Rev Biochem 2004; 73:39-85.

41 Webley K, Bond JA, Jones CJ, Blaydes JP, Craig A, Hupp T, et al. Posttranslational modifications of p53 in replicative senescence overlapping but distinct from those induced by DNA damage. Mol Cell Biol 2000; 20:2803-2808.

42 Maga G, Hubscher U. Proliferating cell nuclear antigen (PCNA): a dancer with many partners. J Cell Sci 2003; 116:3051-3060.

43 Lee MH, Yang HY. Negative regulators of cyclin-dependent kinases and their roles in cancers. Cell Mol Life Sci 2001; 58:1907-1922.

44 Coqueret $\mathrm{O}$. New roles for p21 and p27 cell-cycle inhibitors: a function for each cell compartment? Trends Cell Biol 2003; 13:65-70.

45 Huang $X$, Tran T, Zhang L, Hatcher R, Zhang P. DNA damage-induced mitotic catastrophe is mediated by the Chk1-dependent mitotic exit DNA damage checkpoint. Proc Natl Acad Sci U S A 2005; 102: 1065-1070.

46 Pines J. Mitosis: a matter of getting rid of the right protein at the right time. Trends Cell Biol 2006; 16:55-63.

47 Dimri GP, Lee X, Basile G, Acosta M, Scott G, Roskelley C, et al. A biomarker that identifies senescent human cells in culture and in aging skin in vivo. Proc Natl Acad Sci U S A 1995; 92:9363-9367.

48 Zhou BB, Elledge SJ. The DNA damage response: putting checkpoints in perspective. Nature 2000; 408:433-439.

49 Chen QM. Replicative senescence and oxidant-induced premature senescence. Beyond the control of cell cycle checkpoints. Ann N Y Acad Sci 2000; 908:111-125.

50 Shay JW, Roninson IB. Hallmarks of senescence in carcinogenesis and cancer therapy. Oncogene 2004; 23: 2919-2933. 
51 Bendjennat M, Boulaire J, Jascur T, Brickner H, Barbier V, Sarasin A, et al. UV irradiation triggers ubiquitin-dependent degradation of $\mathrm{p} 21^{\text {(WAF1) }}$ to promote DNA repair. Cell 2003; 114:599-610.

52 Philipp-Staheli J, Payne SR, Kemp CJ. p2 $7^{(\text {Kip1) }}$ : regulation and function of a haploinsufficient tumor suppressor and its misregulation in cancer. Exp Cell Res 2001; 264:148-168.

53 Zhang P, Wong C, Liu D, Finegold M, Harper JW, Elledge SJ. p21 ${ }^{(\mathrm{CIP} 1)}$ and $\mathrm{p} 57^{(\mathrm{KIP} 2)}$ control muscle differentiation at the myogenin step. Genes Dev 1999; 13:213-224
54 Roninson IB. Tumor cell senescence in cancer treatment. Cancer Res 2003; 63:2705-2715

55 Carvalhal AV, Marcelino I, Carrondo MJ. Metabolic changes during cell growth inhibition by p27 overexpression. Appl Microbiol Biotechnol 2003; 63:164-173.

56 Terada $\mathrm{Y}$, Inoshita S, Nakashima O, Tamamori M, Ito H, Kuwahara M, et al. Cell cycle inhibitors ( $\mathrm{p} 27^{\mathrm{Kip} 1}$ and $\mathrm{p} 21^{\mathrm{CIP} 1}$ ) cause hypertrophy in LLC-PK1 cells. Kidney Int 1999; 56:494-501. 